\title{
Early Development of the Gut Microbiome and Immune-Mediated Childhood Disorders
}

\author{
Min Li, $\mathrm{PhD}^{1}$ Mei Wang, $\mathrm{PhD}^{1}$ Sharon M. Donovan, $\mathrm{PhD}, \mathrm{RD}^{1}$ \\ ${ }^{1}$ Department of Food Science and Human Nutrition, University of \\ Illinois, Urbana, Illinois \\ Semin Reprod Med 2014;32:74-86 \\ Address for correspondence Sharon M. Donovan, PhD, RD, \\ Department of Food Science and Human Nutrition, University of \\ Illinois, 339 Bevier Hall, 905 S. Goodwin Avenue, Urbana, IL 61801 \\ (e-mail: sdonovan@illinois.edu).
}

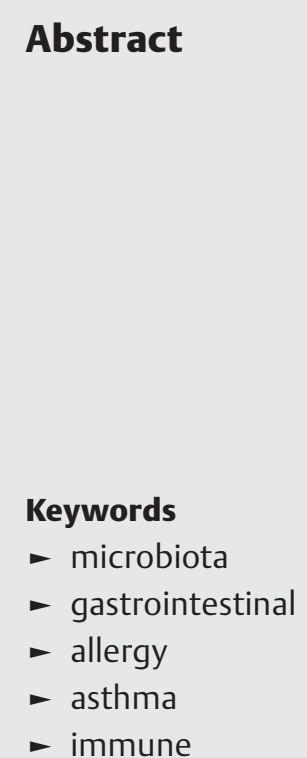

The human gastrointestinal tract inhabits a complex microbial ecosystem that plays a vital role in host health through its contributions to nutrient synthesis and digestion, protection from pathogens, and promoting maturation of host innate and adapt immune systems. The development of gut microbiota primarily occurs during infancy and is influenced by multiple factors, including prenatal exposure; gestational age; mode of delivery; feeding type; pre-, pro-, and antibiotic use; and host genetics. In genetically susceptible individuals, changes in the gut microbiota induced by environmental factors may contribute to the development of immune-related disorders in childhood, including atopic diseases, inflammatory bowel disease, irritable bowel syndrome, and necrotizing enterocolitis. Pre- and probiotics may be useful in the prevention and treatment of some immune-related diseases by modulating gut microbiota and regulating host mucosal immune function. The review will discuss recent findings on the environmental factors that influence development of gut microbiota during infancy and its potential impact on some immune-related diseases in childhood. The use of pre- and probiotics for prevention and intervention of several important diseases in early life will also be reviewed.
Human infants are born with a naive and immature immune system. The maturation of immune system during infancy is evidenced by an induction of a pathogen-specific immune response while maintaining immunological tolerance to dietary components and commensal microbes. ${ }^{1}$ The gastrointestinal tract is the largest immunological tissue in human body and is colonized with a complex microbial community that induce regulatory T cells (Th3 and Th1 cells) via production of suppressive cytokines, transforming growth factor- $\beta$ (TGF- $\beta$ ), and/or interleukin-10 (IL-10), which help to guide a balanced T helper 1 (Th1) and T helper 2 (Th2) response., ${ }^{1,2}$ Failure to develop a balance between immune tolerance and active immune response is hypothesized to contribute to immune-related disorders, such as allergy (Th2 mediated) and inflammatory bowel disease (IBD) (Th1 mediated). ${ }^{3,4}$ In addition, the gut microbiota also stimulates mucosal IgA secretion, produces antibacterial substances, and enhances tight junction of the intestinal barrier, which protect against pathogen invasion in the gut. ${ }^{5}$ Thus, cross talk between intestinal epithelium cells and resident microbiota promotes the immune homeostasis and maturation. ${ }^{6}$

Colonization of the infant gut is initially dominated by facultative anaerobes, such as enterobacteria, enterococci, lactobacilli, and streptococci, followed by anaerobic microbes, such as Bacteroides, bifidobacteria, clostridia, and eubacteria. ${ }^{7}$ By 1 year of age, the infant gut microbiota resembles a complex adult-like pattern. ${ }^{8}$ Development of infant gut microbiota is influenced by prenatal exposure; gestational age; mode of delivery; feeding type; pre-, pro-, and antibiotic use; and host genetics. Alteration of gut microbiota by environmental factors may contribute to the development of immune-related disorders in genetically susceptible infants. ${ }^{9,10}$ Herein, the environment factors influencing the gut microbiota development ( - Fig. 1) and the relationship between the
Issue Theme The Microbiome and Reproduction; Guest Editors, James $\mathrm{H}$. Segars, MD, and Kjersti M. Aagaard, $\mathrm{MD}, \mathrm{PhD}$
Copyright (c) 2014 by Thieme Medical Publishers, Inc., 333 Seventh Avenue, New York, NY 10001, USA. Tel: +1(212) 584-4662. 


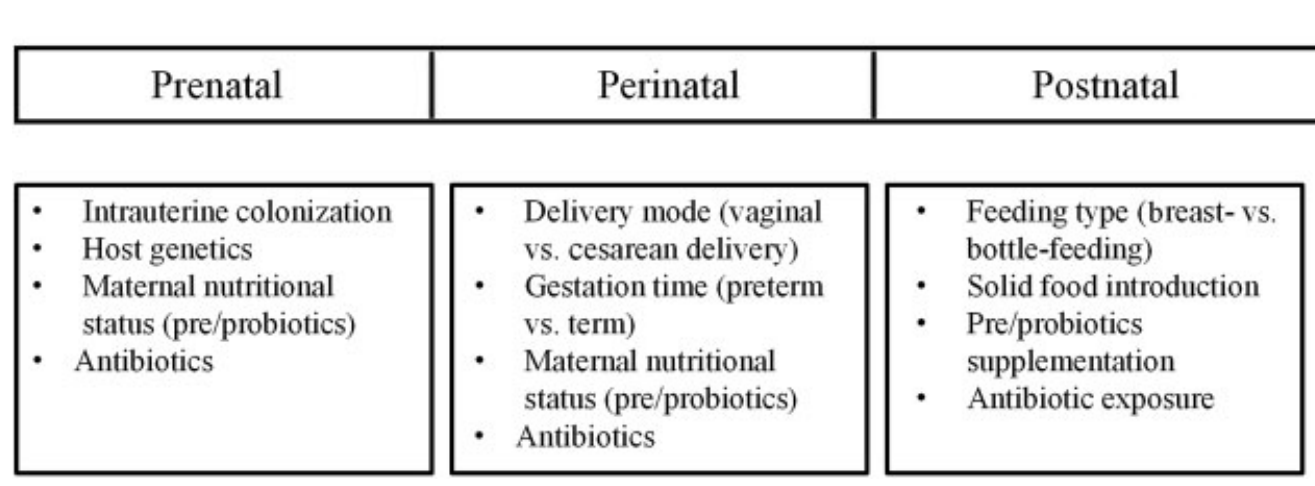

Figure 1 Factors influencing the development of gut microbiota in early infancy.

gut microbiota and immune-related diseases in childhood (-Fig. 2 and - Table $\mathbf{1}$ ) will be reviewed. In addition, the potential for prevention and intervention of several important diseases that develop in early life by pre/probiotics supplementation will be presented.

\section{Factors Influencing the Development of the Gut Microbiota}

\section{Prenatal Exposure}

It is commonly stated that newborns are born with a sterile gastrointestinal tract, and are rapidly colonized by microbes obtained from their mothers and the surrounding environment during and after birth. ${ }^{7}$ However, as early as 1936 , Snyder isolated bacteria, such as Lactobacillus acidophilus, Streptococcus pyogenes, and S. mitis, from the first meconium sample of 3 out of 29 infants within 30-minute after delivery. ${ }^{11}$ Recently, the presence of bacterial isolates and/or DNA, such as lactic acid bacteria, Enterococcus, Staphylococcus, and Bifidobacterium, has been documented in meconium, ${ }^{12} \mathrm{am}-$ niotic fluid, ${ }^{13,14}$ fetal membranes, ${ }^{15}$ umbilical cord blood, ${ }^{16}$ and placenta ${ }^{17,18}$ of the healthy mothers and infants, without any clinical signs of infection or inflammation. These findings suggest that fetuses are not sterile and that prenatal

\section{GUT MICROBIOTA}

Cesarean delivered infants was initially colonized by bacteria from human skin; the early microbiota was less diverse, had lower number of beneficial bacteria, e.g. Bifidobacterium and Bacteroides fragilis group and more often colonized with Clostridium difficile.

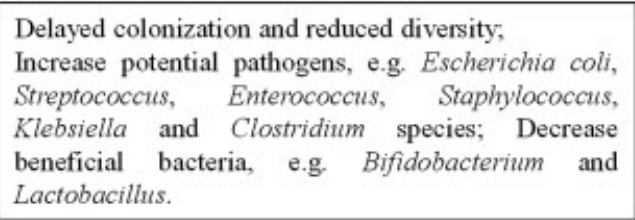
In general, breastfed infants are colonized mainly by Bifidobacterium, while formula-fed infants harbor a more diverse microbiota, including Bacteroides, clostridia, Enterocaccus and Enterobacteriaceae in addition to Bifidobacterium.

Altered microbial colonization; Antibiotic treated infants had less diversity with attenuation of the colonization of some beneficial bacteria, such as Bifidobacterium and overgrowth of potential pathogens, e.g. Enterobacteriaceae.

Prebiotics increase beneficial bacteria counts: e.g. Bifidobacterium and Lactobacillus. Probiotics increase beneficial bacteria: e.g. Lactobacillus; decrease potential pathogens, e.g. Enterobacteriaceae.

\section{ENVIRONMENTAL FACTORS}

\section{IMMUNE-MEDIATED DISORDERS}

\section{$\longrightarrow$ Delivery mode $\longrightarrow \quad$ Increase risk of asthma and food allergy, had no effect on eczema Increase risk of IBD or no effect}

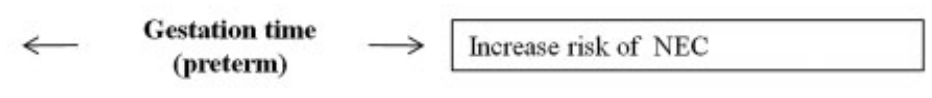

Decrease risk of asthma and food allergy; except when mothers have atopic diseases. For eczema, results are controversy: breastfeeding decreases, has no effect or increases eczema. Protective effect on IBD

Increase risk of asthma, eczema, food allergy, NEC, IBD, IBS

Prebiotics decrease eczema and asthma in infants at high risk of allergy. Combined pre- and postnatal probiotic

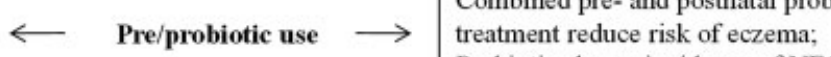
Probiotics lower incidence of NEC. Probiotics induce remission maintenance of ulcerative colitis

Figure 2 Impact of environmental factors on the colonization of gut microbiota and immune-related disorders. Abbreviations: IBD, inflammatory bowel diseases; IBS, irritable bowel syndrome; NEC, necrotizing enterocolitis. 
Table 1 Associations between gut microbiota changes and immune-mediated disorders in childhood

\begin{tabular}{|c|c|}
\hline Immune-mediated disorders & Change in gut microbiota \\
\hline Asthma & $\begin{array}{l}\uparrow \text { Clostridium difficile } \\
\uparrow \text { Bacteroides fragilis subgroup and Clostridium coccoides subcluster XIVa }\end{array}$ \\
\hline Eczema & $\begin{array}{l}\downarrow \text { Bacterial diversity } 91-93 \\
\uparrow \text { B. pseudocatenulatum, Escherichia coli, and C. difficile } \\
72,90\end{array}$ \\
\hline Food allergy (cow milk allergy) & $\begin{array}{l}\uparrow \text { Total and anaerobic bacteria and } \downarrow \text { yeast } \text { count }^{100} \\
\uparrow \text { C. coccoides group and Atopobium } \text { cluster }^{101} \\
\uparrow \text { Bacterial metabolic products, e.g., butyric acid and BCFA }{ }^{101}\end{array}$ \\
\hline NEC & $\begin{array}{l}\uparrow \text { y-Proteobacteria and } \downarrow \text { Firmicutes }^{32} \\
\uparrow \text { Citrobacter-like sequences and Enterococcus-like sequences }^{110} \\
\text { Enterobacter associated with NEC } \\
\text { No significant differences between NEC and control }\end{array}$ \\
\hline IBD & $\begin{array}{l}\uparrow \text { Aerobic and facultative anaerobic bacteria }{ }^{118} \\
\uparrow \text { y-Proteobacteria, }{ }^{117} \text { e.g., adhesive-invasive E. coli }{ }^{119} \\
\downarrow \text { Clostridia, e.g., Faecalibacterium, Bacteroides, e.g., B. vulgatus and bifidobacteria }{ }^{115,116,118}\end{array}$ \\
\hline IBS & $\begin{array}{l}\uparrow \text { v-Proteobacteria, Haemophilus, and Dorea }{ }^{130} \\
\downarrow \text { Eubacterium and Anaerovorax } 130 \\
\uparrow \text { Veillonella, Prevotella, Lactobacillus, and Parasporobacterium in children with IBS-D }{ }^{131} \\
\downarrow \text { Bifidobacterium and Verrucomicrobium in children with IBS-D }{ }^{131}\end{array}$ \\
\hline
\end{tabular}

Abbreviations: IBD, inflammatory bowel disease; IBS, irritable bowel syndrome; IBS-D, diarrhea-predominant irritable bowel syndrome; NEC, necrotizing enterocolitis; BCFA, branched-chain fatty acids.

transmission of bacteria from mother to fetus exists in healthy pregnancies. ${ }^{12,19}$

Although the mechanism of transfer in humans is still unclear, a genetically labeled Enterococcus faecium strain orally inoculated to pregnant mice was detected in amniotic fluid and in meconium of the pups, ${ }^{12,16}$ indicating that maternal gut microbes might be the origin of the first colonizers in fetal gut. ${ }^{12}$ Additionally, dendritic cells in Peyer patches penetrate the junctions between gut epithelial M cells to directly take up bacteria from maternal gut lumen, and then enter into the lymphatic and blood circulation. Once in the circulation, the bacteria may be transferred to the fetus cross placental barrier, and initiate the first colonization of fetal gut. ${ }^{19,20}$ Furthermore, other studies found that bacteria in the maternal mouth could reach the amniotic fluid via the bloodstream, particularly in the presence of gingivitis or periodontitis during pregnancy. ${ }^{21}$ Taken together, these studies support the concept that the maternal microbiota seeds prenatal colonization of the human infant gut, which may stimulate the fetal intestinal mucosal immune system in utero. $^{20,22}$

\section{Gestational Age}

Postconceptional age at delivery is another factor affecting infant gut microbial colonization. The gut microbiota of preterm infants is often colonized more slowly, has higher interindividual variability and lower diversity than that of healthy full-term infants. ${ }^{23,24}$ The early colonizers in preterm infant gut are often potential pathogens, such as Escherichia coli, Streptococcus, Enterococcus, Staphylococcus, Klebsiella, and Clostridium species. ${ }^{23,25-27}$ The beneficial bacteria, for example, Bifidobacterium and Lactobacillus, which are commonly found in healthy full-term infants, were rarely de- tected or were present at low numbers in the stool of preterm infants. $^{25,26,28}$ The delayed colonization and reduced diversity of gut microbiota in preterm infants might be due to the aseptic environment, the neonatal intensive care unit, and delayed oral feeding. ${ }^{29,30}$ In addition, the extensive use of antibiotics in preterm infants may also be an important factor causing the disturbance of gut microbiota, ${ }^{26,29}$ and may consequently lead the preterm infant to be more susceptible to gastrointestinal disorders and disease, such as necrotizing enterocolitis (NEC). ${ }^{31,32}$

\section{Delivery Mode}

How an infant is delivered is also associated with the early colonization of microbiota. A recent study compared the fecal microbiota of newborn infants within 24 hours of delivery with the microbiota of their mother' skin, oral mucosa, and vagina by $16 \mathrm{~S}$ rDNA pyrosequencing ${ }^{33}$ and showed that the fecal bacterial composition of vaginally delivered (VD) infants was most similar to that of vaginal communities of the mothers, with Lactobacillus, Prevotella, and Atopobium spp. predominating. In contrast, the fecal bacterial composition of cesarean delivery (CsD) infants was most similar to the maternal skin, with an abundance of Staphylococcus and Corynebacterium. Thus, initial colonization is determined to a large extent by the first abundant microbes that an infant counters, from maternal vagina, feces, or skin. In addition, the microbiota of CsD infants is less diverse than that of VD infants at 3 days of age. ${ }^{34}$ There was an absence of Bifidobacterium spp. in the stool of CsD infants, whereas VD infant stool was predominated by Bifidobacterium longum and B. catenulatum. ${ }^{34}$ In another study, CsD infants had lower numbers of Bifidobacterium and Bacteroides fragilis group, and were more often colonized with Clostridium difficile compared with VD 
infants. ${ }^{35}$ Although differences in early microbiota between CsD and VD infants are well documented, the long-term impact of early colonization on subsequent childhood immune development and disease outcomes are not fully understood and shown to be investigated in a long-term prospective cohort study.

\section{Diet}

Feeding mode is one of the most important determinants of gut microbial diversity; however, its impact on the infant microbiota is often contradictory. Many studies have shown that breastfed (BF) infants are colonized mainly by Bifidobacterium, while formula-fed (FF) infants harbor a more diverse microbiota, including Bacteroides, clostridia, Enterococcus, and Enterobacteriaceae in addition to Bifidobacterium. ${ }^{36,37}$ Other studies have shown that Bifidobacterium are found equally often and in similar counts in BF and FF infants. ${ }^{38}$ These inconsistencies may arise from the different analytical approaches used in enumerating the microbiota or the variability in the composition of the human milk and infant formula that the infants are consuming and geographically distinct infant groups.

Differences in microbial diversity between BF and FF infants may reflect the prebiotic effects of the large quantity of structurally diverse human milk oligosaccharides (HMO), ${ }^{39}$ which are negligible in bovine milk and infant formula. ${ }^{40}$ The HMO can function as prebiotics to stimulate the growth of specific gut bacteria, including Bifidobacterium and Bacteroides species in vitro. ${ }^{41,42}$ Moreover, human milk contains bacteria such as Staphylococcus, Streptococcus, Bifidobacterium, and Lactobacillus ${ }^{43}$ that may serve as a diverse and continuous source of live microbes for the infant gut.

Introduction of solid food causes rapid and sustained alterations in the gut microbiota of infants. Koenig et al catalogued the gut microbiome of one infant over 2.5-year period by $16 \mathrm{~S}$ rDNA pyrosequencing and found that introduction of table foods to the diet of the BF infant at approximately 5 months of age induced a sustained increase in the abundance of Bacteroidetes. ${ }^{44}$ Fallani et al examined the composition of fecal microbiota of 531 infants before weaning and 4 weeks after the introduction of first solid food by fluorescence in situ hybridization (FISH) and reported that weaning significantly increased the proportion of Clostridium coccoides and C. leptum groups but decreased Bifidobacterium, Enterobacteria, C. perfringens, and C. difficile. ${ }^{45}$

\section{Pre-, Pro-, and Antibiotics}

The composition of the infant's gut microbiota can be influenced by the use of prebiotics, probiotics, and antibiotics. A prebiotic is defined as "a selectively fermented ingredient that results in specific changes, in the composition and/or activity of the gastrointestinal microbiota, thus conferring benefit(s) upon host health." 46 Several groups have reported that supplementation of infant formula with prebiotics affected the composition of the gut microbiota. ${ }^{47-49}$ For example, infants fed an infant formula containing a combination of $90 \%$ short-chain galactooligosaccharides (scGOS) and 10\% long-chain fructooligosaccharides (lcFOS) had increased fecal bifidobacteria and lactobacilli counts. ${ }^{47,49}$ Investigations into the effect of prebiotic supplementation during pregnancy on the composition of neonatal microbiota are rare. In a randomized, double-bind, placebo-controlled trail, supplementation of $9 \mathrm{~g} / \mathrm{d}$ scGOS and lcFOS (9:1 ratio) to mothers in the last trimester of pregnancy resulted in an increase in the relative abundances of bifidobacteria and lactobacilli in the maternal gut, with no effect on the gut microbiota of their offspring. ${ }^{50}$ A limitation of the study was that only bifidobacteria and lactobacilli were investigated, and the impact of maternal prebiotic treatment on other bacteria remained unknown. Furthermore, the authors did not separate BF from FF infants; therefore, the lack of effect of the prebiotic supplementation to the mother on infant stool could be due to the HMO consumed by the BF infants.

According to $\mathrm{FAO} / \mathrm{WHO},{ }^{51}$ probiotics are "live microorganisms which, when consumed in adequate amounts, confer a health benefit on the host." A recent Finnish study investigated probiotic administration to the mother on the infant's microbiota at 6 months of age using FISH and quantitative PCR (qPCR). ${ }^{52}$ The gut microbiota of BF infants whose mothers received Lactobacillus rhamnosus LPR together with $B$. longum BL999 for 2 months before and 2 months after delivery had higher abundance of lactobacilli, enterococci and lower counts of Bifidobacterium compared with infants of mothers receiving a placebo treatment. When the same probiotic combination was administered directly to German FF infants for 4 months, the effect of the probiotics on microbiota composition was minor; however, Bifidobacterium bifidum count was lowered compared with the placebo group, which is consistent with the previous study.

In contrast, antibiotics exert detrimental effects on infant microbiota composition. Using terminal restriction fragment length polymorphism (T-RFLP) analysis and qPCR, Tanaka et $\mathrm{al}^{53}$ monitored the impact of cephalexin exposure in the first 4 days of life on the development of intestinal microbiota. Cephalexin-treated infants had reduced overall diversity, with a specific reduction of Bifidobacterium and overgrowth of Enterococcus and Enterobacteriaceae in the first month of life compared with untreated infants. ${ }^{53}$ Whether antibiotic administration to the mother affects the microbiota of their infant has also been studied. If a mother was treated with ampicillin and gentamicin within 48 hours of birth, her infant had a higher proportion of Proteobacteria and a lower proportion of Actinobacteria and genus Lactobacillus 4 weeks after the cessation of treatment compared with infants of untreated mothers. Importantly, the Proteobacteria level remained elevated in the infants of treated mothers 8 weeks posttreatment, suggesting long-term effects on microbial populations. $^{54}$

\section{Host Genetics}

The earliest study to show a relationship between host genotype and gut microbiota in children was conducted in 1983 using cultivation-dependent methods, and found that the fecal microbiota of monozygotic (MZ) twin siblings was more similar than that of dizygotic (DZ) twin siblings. ${ }^{55}$ Later studies revealed higher similarity of gut microbiota in MZ 
twins than in DZ twins and/or unrelated individuals. ${ }^{56,57}$ Palmer et al also found that the gut microbiota was more similar in DZ twins than in unrelated children at any stage of development over the first year of life. ${ }^{8}$ In contrast, Turnbaugh et al reported that the similarity of fecal microbiota in MZ twin pairs was not different from that in DZ twin pairs as assessed by next generation $16 \mathrm{~S}$ rDNA pyrosequencing. ${ }^{58}$ Although the results of twins studies appear equivocal, other studies have confirmed that the gut microbiota of genetically related children is more similar than those of unrelated individuals, ${ }^{8,56,58}$ indicating that host genetics must play an important role in the selection and colonization of gut microbes in humans.

Clear evidence linking host genetics and the microbiota has been obtained in mice. Work in a mouse advanced intercross line originating from a cross between C57BL/6J and an ICR-derived outbred line mice demonstrated a relationship between host genetics and the "core measurable microbiota (CMM)" of 64 conserved taxonomic groups that varied quantitatively across most animals. ${ }^{59}$ Testing of the CMM abundances for cosegregation with 530 fully informative single nucleotide polymorphism (SNP) markers identified 18 host quantitative trait loci (QTL) that showed significant or suggestive genome-wide linkage with relative abundances of specific microbial taxa. Some of the loci controlled individual microbial species, several controlled groups of related taxa, and others had putative pleiotropic effects on groups of distantly related organisms. Recently, the same group showed that microbial diversity was influenced by both environmental and host genetic factors and was associated with several polygenic diseases in BXD recombinant inbred mice. ${ }^{60}$ The gut microbial composition differed among BXD strains and linkage analysis defined QTLs that were either restricted to a particular taxon or that influenced the variation of taxa across phyla. A QTL region on chromosome 4 that overlapped several interferon genes modulated the population of Bacteroides, and potentially Bacteroidetes and Firmicutes-the predominant BXD gut phyla. Irak4, a signaling molecule in the Toll-like receptor pathways, was a candidate for the QTL on chromosome15 that modulated Rikenellaceae, whereas TGF- $\beta 3$, a cytokine that modulates intestinal barrier function and tolerance to commensal bacteria, overlapped a QTL on chromosome 12 that influenced Prevotellaceae. These findings provide clear evidence for the importance of host genetics in shaping microbiome diversity and contribute to our understanding of the host factors that govern the assemblages of gut microbiota associated with complex diseases in mice.

\section{Interaction between the Gut Microbiota, Immunity, and Immune-Related Disorders}

The gut microbiota plays important roles in shaping the immune system during infancy. The commensal microbes and their products interact with immune cells to create and maintain host tolerance and influence both innate and adaptive immune response. ${ }^{61-63}$ Mounting evidence shows that dysbiosis is associated with the development of immune- mediated diseases, such as allergy, irritable bowel syndrome (IBS), NEC, and IBD.

\section{Allergic Diseases}

The prevalence of allergic diseases has been increasing in industrialized countries over the past few decades. ${ }^{64,65}$ The dichotomy in the rate of allergic diseases between industrialized and developing countries suggests that environmental changes associated with a western lifestyle are the major factor in the development of allergic diseases. ${ }^{66,67}$ In 1988 , Strachan first introduced the "hygiene hypothesis," which states that lack of early microbial exposure increases susceptibility to allergic diseases by suppressing natural development of the immune system. ${ }^{68}$ Numerous epidemiologic and clinical studies have demonstrated that the composition of the gut microbiota differs between allergic and nonallergic children, even before the emergence of symptoms. ${ }^{69-72}$ Gut microbes induce regulatory $\mathrm{T}$ cells that influence Th1 and Th2 balance and help prevent aberrant immune response. ${ }^{73}$ Therefore, an alternative hypothesis, that is, the "microbiota hypothesis," has been generated, which proposes that alteration of the gut microbiota due to antibiotic use, diet, or lifestyle changes disrupts the normal microbially mediated mechanisms of immunological tolerance, leading to an increase in the incidence of allergic diseases including asthma, eczema, and food allergy in later childhood. ${ }^{74,75}$

Asthma, a chronic inflammatory disorder of the airway, is often thought to be caused by a combination of genetic and environmental factors. A prospective birth cohort study that analyzed nearly 1,000 infants reported that differences in gut microbiota in the first month of life was predictive of subsequent development of recurrent wheeze at 2 years of age, and C. difficile was particularly associated with the increase of asthma. ${ }^{72}$ In another study, Vael et al identified $B$. fragilis subgroup and $C$. coccoides subcluster XIVa in the gut microbiota of infants as early indicators of risk of asthma later in life. ${ }^{76}$

There is growing interest in exploring which environmental exposures influence the development of asthma via modulation of gut microbiota. For example, CsD infants had a higher risk of asthma compared with VD infants, ${ }^{77,78}$ and were more frequently colonized by the asthma-associated pathogen, $C$. difficile. ${ }^{35}$ van Nimwegen et al, who first explored the delivery mode-gut microbiota-asthma pathway confirmed that the effect of CsD on asthma development was mediated by $C$. difficile in the gut. ${ }^{79}$ Use of antibiotics in early life is another factor associated with the increased risk for wheeze or asthma, ${ }^{80,81}$ apparently by suppressing commensal gut bacteria and causing the growth of pathogens, for example, $C$. difficile. In mice, Vancomycin in early life disrupted the microbiota and enhanced susceptibility to ovalbumin-induced asthma. ${ }^{82}$ In contrast to the adverse effect of CsD and antibiotics on gut microbiota and asthma, breastfeeding favors beneficial bacteria colonization in the infant gut, for example, Bifidobacterium, and protects against asthma in later childhood. ${ }^{83,84}$ However, the protection afforded by breastfeeding was not observed in infants whose mother has atopic diseases. ${ }^{85,86}$ One possible reason may be related to low amount of bifidobacteria in the breast milk of allergic 
mothers, which may have caused their infants to concurrently have lower counts of bifidobacteria in the gut, ${ }^{87}$ and possibly greater susceptibility to asthma in later childhood.

Eczema (atopic dermatitis) is a chronic, inflammatory skin diseases, affecting at least $10 \%$ of U.S. children, and its prevalence has increased over the past a few decades. ${ }^{88,89}$ A study performed in the Netherlands with 957 infants documented that $E$. coli and $C$. difficile in feces at 1 month of age was associated with higher risk of developing eczema, ${ }^{72}$ while Gore et al compared Bifidobacterium spp. in the feces of infants at 3 to 6 months of age and showed that B. pseudocatenulatum was more commonly detected in the feces of children with eczema. ${ }^{90}$ Using temperature gradient gel electrophoresis and T-RFLP, Wang et al examined overall patterns of fecal microbial colonization in healthy $(n=20)$ and atopic $(n=15)$ infants and found that infants who developed eczema had significantly lower fecal bacterial diversity at 1 week of age than infants who remained healthy for 18 months. ${ }^{91}$ Others have confirmed that a less diverse intestinal microbiota in early life was associated with an increased risk of eczema. ${ }^{92,93}$ Thus, diversity of the gut microbiota in early childhood may be more important than an altered prevalence of particular bacterial species for the increasing incidence of eczema. Recently, studies have investigated the association between environmental factors that influences the colonization of microbiota and eczema. For example, a multicenter, multicountry cross-sectional study (Phase III of ISAAC) of 193,412 children showed an association between antibiotic use in the first year of life and symptoms of eczema in 6- and 7-year-old children. ${ }^{94}$ The impact of feeding mode on the development of eczema was also studied, but the results are controversial. Several studies showed exclusive breastfeeding for at least 3 months protected against the development of eczema in infants with a family history of atopy. ${ }^{95,96}$ Other studies have not found a protective role of breastfeeding and some found that breastfeeding increased the risk of eczema. ${ }^{97,98}$

Food allergy is defined as an adverse immune reaction to a food protein, such as those found in milk, egg, and wheat, which causes dermatitis, gastrointestinal, and respiratory disorders. ${ }^{99}$ Several studies have shown an association between altered gut microbiota and the development of food allergy. A prospective study that compared the fecal microbiota of children immediately after diagnosis of cow milk allergy found higher amounts of total and anaerobic bacteria and lower yeast counts ${ }^{100}$ compared with healthy children. Furthermore, using FISH combined with flow cytometry, the same group found that the amount of $C$. coccoides group and Atopobium cluster and bacterial metabolic products, butyrate and branched-chain fatty acids, were higher in children with cow milk allergy compared with healthy infants. ${ }^{101}$ In addition, a germfree (GF) mouse model of cow milk allergy revealed that GF mice were more responsive than conventional mice to oral sensitization and challenge with $\beta$-lactoglobulin, ${ }^{102}$ while GF mice colonized with an infant fecal microbiota, which was dominated by Bifidobacterium and Bacteroides, were protected against cow milk allergy via the mechanism of increasing foxp3 gene expression, which is the master regulatory molecule in Treg cell function. ${ }^{103}$ It has been proposed that changes in gut microbiota resulting from CsD might correlate to the increased risk of developing food allergy in children. Some studies found that CsD children have a higher risk of food allergy, ${ }^{61,104}$ while other studies did not detect significant association between delivery mode and prevalence of food allergy ${ }^{105}$ in offspring of atopic mothers. ${ }^{106,107}$ Thus, the impact of CsD and other environmental factors on gut microbiota and food allergy should be further investigated in prospective trials.

\section{Necrotizing Enterocolitis}

NEC is a major cause of morbidity and mortality in low-birthweight infants, afflicting $7 \%$ of infants weighing less that $1,500 \mathrm{~g}$, with a mortality rate of 20 to $30 \%{ }^{108}$ Preterm delivery is the main risk factor for NEC, presumably due to immaturity of gastrointestinal motility, barrier function, and immune defense. Enteral feeding with infant formula constitutes another important risk factor, whereas breast milk is protective against NEC. ${ }^{108,109}$ The gut bacteria have been shown to be causative for NEC in animal models and dysbiosis is associative with NEC in preterm infants. ${ }^{32,110-112}$ Although several bacteria, viruses, and fungi have been found to cause NEC in human and animal studies, no single change or even pattern of change in the gut microbiota has been consistently identified as a risk factor for NEC. ${ }^{108}$ Even investigations conducted by the same research group using the same sequencing approach (454 pyrosequencing) have shown differences in the microbial signatures associated with NEC. For example, Mshvildadze et al detected Citrobacter-like sequences only in cases with NEC and an increased frequency of Enterococcus-like sequences in cases with Klebsiella in control subjects. ${ }^{110}$ However, in a subsequent publication, ${ }^{32}$ one of the bacterial signatures detected more frequently in NEC cases matched closest to $\gamma$-Proteobacteria and the same Citrobacter-like sequences were not detected in infants with NEC. In a prospective single-center case-control study, Norman et al mapped the bacterial composition of fecal samples from 20 extremely preterm infants (10 NEC and 10 matched healthy controls). No significant differences were observed between NEC and controls; however, a higher Bacillales and Enterobacteriaceae relative abundance was detected at early time points in infants who developed NEC, while healthy controls were more dominated by Enterococcus. ${ }^{111}$ Stewart et al found that bacterial community structures in infants with NEC and late onset sepsis differed from healthy preterm infants. The presence of Enterobacteria and Staphylococcus was associated with the development of NEC and late onset sepsis, respectively. ${ }^{112}$ Differences in these studies are likely due to the fact that NEC represents a clinical scenario that can arise from several bacterial etiologies that can vary among neonatal intensive care unit and that most studies involved a limited number of subjects (6-40 cases and controls). Overall, the clinical evidence suggests that NEC does not result from growth of a single causative pathogen, but rather that the disease results from a generalized disturbance of normal colonization patterns in the developing gut. ${ }^{108}$ However, findings of prospective studies documented 
detectable changes in the microbiota of infants before the onset of NEC. ${ }^{32,112}$ Mai et al found phyla-level shifts in fecal microbial signatures of infants who developed NEC that occurred between 1 week and 3 days before the diagnosis of NEC. ${ }^{32}$ Using principal coordination analysis to study bacterial community structure, Stewart et al demonstrated that profiles from healthy infants were distributed separately from those infants with NEC and/or late onset sepsis, and samples collected before NEC onset also showed a distinct cluster. ${ }^{112}$ These findings suggest that bacterial changes may trigger alterations in host immunity and/or barrier function that subsequently lead to the clinical signs and symptoms of NEC.

\section{Inflammatory Bowel Disease}

IBDs, including Crohn disease (CD) and ulcerative colitis (UC), are chronic inflammation of the small bowel and/or colon leading to recurrent diarrhea and abdominal pain. Complex interactions between host genetics, mucosal immune system, and enteric microbes are thought to underlie the development of IBD. ${ }^{113}$ Differences in the composition of the gut microbiota between IBD patients and healthy control have been shown, leading to the hypothesis that dysbiosis could contribute to the etiology and pathogenesis of IBD. ${ }^{114}$ Two studies comparing the fecal microbiota of children with $C D$ and UC with healthy controls using culture-based methods, combined with qPCR and T-RFLP, found that the overall fecal microbiota diversity was reduced in $C D$ patients, with specific reductions in the number of commensal bacteria, such as Faecalibacterium, Bacteroides and bifidobacteria, and increased number of $E$. coli compared with healthy children. No major changes were detected in UC patients, except for a decrease in bifidobacteria in the active state of UC. ${ }^{115,116}$ Recently, Michail et al confirmed these results in patients with severe UC. The fecal microbial diversity was lower in UC children with a reduction in clostridia and an increase in $\gamma$ Proteobacteria compared with healthy controls. ${ }^{117}$ Several studies have examined the mucosal-associated microbiota in subjects with IBD and also showed similar results. Conte et al found a higher number of aerobic and facultative anaerobic bacteria in ileal, cecal, and rectal biopsies from children with IBD and a decrease in Bacteroides vulgatus. ${ }^{118}$ Negroni et al also detected two adhesive-invasive $E$. coli strains in the inflamed tissues of children with IBD, further supporting their role in the pathogenesis of IBD. ${ }^{119}$ Several environmental factors may contribute to the risk of IBD in childhood. A Danish national cohort study showed that CsD was associated with increased risk of IBD at age 0 to 14 years, ${ }^{120}$ while a German case-control study including 2,000 children and young adolescents did not find any association between delivery mode and IBD. ${ }^{121}$ In terms of early nutrition, two systemic reviews using meta-analysis showed that breastfeeding was associated with lower risk of UC and CD in childhood. ${ }^{122,123}$ In contrast, antibiotic use in early life has been shown to associate with a high risk of IBD development, ${ }^{124-126}$ although most studies found an association with antibiotic use only in children with $C D$, not in UC children. ${ }^{125-127}$ For additional information on the influence of environmental factors on the development of pediatric IBD, readers are referred to a recent review by Aujnarain et al. ${ }^{128}$

\section{Irritable Bowel Syndrome}

IBS is a functional bowel disorder characterized by abdominal pain or discomfort that is associated with altered bowel habit. ${ }^{129}$ The pathophysiology of IBS is poorly understood; however, changes in the composition of gut microbiota have been linked to IBS. ${ }^{130,131}$ Saulnier et al compared fecal microbiota of patients with IBS and healthy controls by 16S rDNA pyrosequencing and microarray, and reported that children with IBS had a greater abundance of the class $\gamma$-Proteobacteria compared with controls. Furthermore, genera of Haemophilus and Dorea were increased, while Eubacterium and Anaerovorax were reduced in IBS children. ${ }^{130}$ Rigsbee et al investigated the fecal microbiota of children with diarrheapredominant IBS. Compared with healthy subjects, higher levels of Veillonella, Prevotella, Lactobacillus, and Parasporobacterium and lower levels of Bifidobacterium and Verrucomicrobium were found in children with IBS. ${ }^{131}$ Few studies have examined the link between environmental factors that impacts the colonization of microbiota and IBS; however, a prospective community-based study found that subjects who were given a course of antibiotics were more than three times as likely to report more functional bowel symptoms 4 months later than nonantibiotic-treated controls. ${ }^{132}$

\section{Prebiotics and Probiotics on the Prevention and Treatment of Immune-Related Disease}

\section{Allergic Disease}

The literature surrounding probiotics and allergic diseases is equivocal, which may be related to considerable variations in the probiotic strains used, daily doses administered, and the timing of administration. ${ }^{133}$ Several meta-analyses have evaluated probiotics for prevention of eczema in children, and most of studies involved combined pre- and postnatal treatment. ${ }^{133,134}$ The majority of combined pre- and postnatal studies demonstrated that probiotics reduced incidence of eczema during first 2 years of life, but a few studies found that probiotics had no beneficial effect on eczema. ${ }^{133}$ Most studies examining either prenatal or postnatal probiotic treatment found no eczema-preventative effect, ${ }^{135-137}$ except one study that reported a reduced incidence of eczema after postnatal treatment with L. paracasei F19. ${ }^{138}$ Several studies showed that administration of probiotics was associated with reduced eczema severity (SCORing Atopic Dermatitis, SCORAD) in children with eczema ${ }^{139,140}$; however, other studies did not show any effect of probiotics on the incidence or severity of eczema. $^{141}$

A few studies investigated the role of probiotics on asthma and most of these reported that probiotics had no effect on the prevention or treatment of asthma/wheezing during first 2 years of life. ${ }^{134}$ Clinical trials of probiotics for the treatment of food allergy are limited and no protective effect has thus far been reported. ${ }^{133}$ A meta-analysis that reviewed the effect of prebiotics given to infants for the prevention of eczema and asthma reported a significant reduction in eczema and 
asthma in infants at high risk of allergy up to 2 years of age; however, no protective effect was found when children were not selected for allergy risk. ${ }^{142}$ Thus, future randomized, controlled, double-blind studies to examine the efficacy of probiotics for both prevention and treatment of food allergies are warranted.

\section{Inflammatory Bowel Diseases}

Probiotics have been used in the treatment of IBD in children; however, their efficacy is inconsistent. In a small, open-label pilot study, Gupta et al showed that Lactobacillus GG (LGG) administered to children with mildly to moderately active, but stable, $\mathrm{CD}$ improved gut barrier function and clinical status. ${ }^{143}$ However, in a later randomized clinical trial, administration of LGG to children with $C D$ in remission for 2 years did not show any efficacy of LGG compared with placebo treatment. ${ }^{144}$ Studies conducted on the effects of probiotics in $\mathrm{CD}$ in adults have also shown negative results. ${ }^{145,146}$

In contrast, the efficacy of probiotics in UC seems to be better than in $\mathrm{CD}$. Miele et $\mathrm{a}^{147}$ conducted the first pediatric randomized, placebo-controlled trial in which children with a newly diagnosed UC received either a highly concentrated mixture of probiotic bacterial strains (VSL\#3 containing $L$. paracasei, L. plantarum, L. acidophilus, L. delbrueckii subsp. bulgaricus, B. longum, B. breve, B. infantis, and Streptococcus salivarius subsp. thermophiles) or a placebo in conjunction with concomitant steroid induction and mesalamine maintenance treatment. Children treated with VSL\#3 had a significantly higher rate of remission and a lower incidence of relapse within 1 year of follow-up compared with the placebo group. ${ }^{147}$ The efficacy of VSL\#3 in inducing/maintaining the UC remission was also confirmed by an open-label pilot study in children ${ }^{148}$ and in clinical trials in adults. ${ }^{149,150}$ In addition to oral administration, rectal infusion of $L$. reuteri in children with active distal UC reduced mucosal inflammation and changed mucosal cytokine expression. ${ }^{151}$ Thus, a consensus for "Probiotic Use-2011 update" recommended the use of probiotics, such as VSL\#3, for maintaining remission of UC, ${ }^{152}$ while there is no basis for recommending the use of probiotics in $\mathrm{CD}{ }^{153}$

A few pilot studies have examined the use of prebiotics, such as inulin, ${ }^{154}$ germinated barley foodstuff, ${ }^{155}$ and FOS $^{156}$ in the treatment of IBD in adults and showed similarly positive results; however, no study in children has been reported and the efficacy of prebiotics remains to be further investigated in clinical trials.

\section{Irritable Bowel Syndrome}

The effect of probiotics on the treatment of IBS in adults has been studied extensively, but data in children are limited and the results are inconsistent. ${ }^{157,158}$ Several reports indicated that probiotic treatment had no effect on global symptoms of IBS in children ${ }^{159}$; however, recent studies demonstrated improvement of symptoms following probiotics. ${ }^{160,161}$ For example, in a randomized, double-blind, placebo-controlled trial in 141 children with IBS or functional pain, LGG significantly reduced the frequency and severity of abdominal pain in children with IBS. ${ }^{160}$ In contrast to probiotics, few studies investigated prebiotics on IBS $^{158}$ and to our knowledge, no data in children were reported. Several studies suggested that supplementation of low dose of prebiotics, for example, FOS or GOS, may be effective, while high doses may have a negative impact on symptoms. A recent study advised that reducing intake of fermentable carbohydrates, including FOS and GOS, may actually improve symptom in IBS. ${ }^{162}$

\section{Necrotizing Enterocolitis}

Probiotic use to reduce NEC has been the subject of several recent reviews. ${ }^{163-165}$ A 2011 Cochrane review based on 16 trials (2,842 infants) concluded that enteral probiotic supplementation to preterm infants less than $2,500 \mathrm{~g}$ birth weight significantly reduced the incidence of severe NEC (stage II or more) and mortality. ${ }^{163}$ Based on the 2011 Cochrane review, the American Pediatric Surgical Association Outcomes and Clinical trial Committee advised the use of probiotics to decrease the incidence of NEC. ${ }^{164}$ However, recently published clinical guidelines from the American Society for Parenteral and Enteral Nutrition did not support the use of probiotics in infants at risk for NEC, and suggested that further studies are necessary to determine the most effective type(s) of probiotic, effective dosage, and duration of treatment. ${ }^{165}$ Studies of prebiotics on the prevention of NEC are rare, and, to the best of our knowledge, there is no clinical evidence supporting the use of prebiotics to prevent NEC. ${ }^{166,167}$

\section{Conclusions and Future Needs}

Accumulating evidence provides strong associations between the gut microbiota, dysregulation of mucosal and systemic immune function, and increased risk of immune-related diseases in children. However, these relationships are multifaceted and are mediated through a complex interaction between the child's genetic background, which dictates the child's risk for developing the disorder and the composition of his/her microbiota and pre-, peri-, and postnatal environmental factors. Most of these environmental factors are amenable to clinical intervention, for example, reducing preterm births, CsD, and the use of antibiotics and promoting breastfeeding and potentially pre- and probiotics. However, to maximize the clinical benefit, a richer understanding of the causal relationships among these factors and the incidence and severity of the immune-related disease is needed.

In general, a reduction in overall bacterial diversity, reduced abundance of commensal bacteria, and increased abundance of potentially pathogenic bacteria has been associated with the immune-related disorders reviewed herein. In some cases, specific bacteria have been identified in cases versus controls (-Table 1); however, there is a lack of consistency between studies, which may be attributable to the small numbers of subjects included in most studies, differences in analytical approaches; even among 16s rDNA-based approaches (qPCR, DGGE, T-RFLP, 454 Pyrosequencing) and between Pyrosequencing and next generation sequencing technologies. To better define the role of the 
microbiota, researchers are encouraged to work together in multicenter prospective trials and to incorporate randomized, placebo-controlled, double-blind study design into future clinical interventions, testing the efficacy of pre- and probiotic interventions. In addition, future investigations should extend beyond descriptions of the composition of the fecal microbiota to incorporate metagenomic and metatranscriptomic analyses, which will provide insight into microbial metabolism. Investigations into the gut virome and fungiome may also provide unique insights into the additional aspects of dysbiosis, underlying disease onset and severity. Additionally, coordinate analysis of host-microbe interactions are needed in both health and disease. For example, using exfoliated epithelial cells, recent work in our laboratory has shown relationship between host intestinal gene expression ${ }^{168}$ and bacterial metagenome virulence factors in BF and FF infants. ${ }^{169}$ This noninvasive approach facilitates investigations into host-microbiome interactions in infants and children and is also amenable to longitudinal studies of cases of chronic inflammation-for example, relationships between gut gene expression and bacterial composition and gene expression could be investigated during phases of disease activity or clinical remission in IBD or responses before and after pre- or probiotic treatments could be assessed. Finally, based on research in rodent models demonstrating genome-wide linkage with relative abundances of specific microbial taxa, future research investigating specific disease-related QTL and the composition of the microbiota are warranted in children with diseases such as IBD.

\section{Acknowledgment}

This study was supported by NIH grant HD061929 to S.M.D. The first two authors contributed equally to the manuscript and are listed alphabetically.

\section{References}

1 Rautava S, Isolauri E. The development of gut immune responses and gut microbiota: effects of probiotics in prevention and treatment of allergic disease. Curr Issues Intest Microbiol 2002; $3(1): 15-22$

2 Donovan S. Role of human milk components in gastrointestinal development: Current knowledge and future NEEDS. J Pediatr 2006;149(5):S49-S61

3 Field CJ. The immunological components of human milk and their effect on immune development in infants. J Nutr 2005;135(1): $1-4$

4 Azad MB, Kozyrskyj AL. Perinatal programming of asthma: the role of gut microbiota. Clin Dev Immunol 2012;2012:932072

5 Forchielli ML, Walker WA. The role of gut-associated lymphoid tissues and mucosal defence. Br J Nutr 2005;93(Suppl 1): S41-S48

6 Dupaul-Chicoine J, Dagenais M, Saleh M. Crosstalk between the intestinal microbiota and the innate immune system in intestinal homeostasis and inflammatory bowel disease. Inflamm Bowel Dis 2013;19(10):2227-2237

7 Mackie RI, Sghir A, Gaskins HR. Developmental microbial ecology of the neonatal gastrointestinal tract. Am J Clin Nutr 1999;69(5): 1035S-1045S
8 Palmer C, Bik EM, DiGiulio DB, Relman DA, Brown PO. Development of the human infant intestinal microbiota. PLoS Biol 2007; 5(7):e177

9 Iebba V, Aloi M, Civitelli F, Cucchiara S. Gut microbiota and pediatric disease. Dig Dis 2011;29(6):531-539

10 Weber TK, Polanco I. Gastrointestinal microbiota and some children diseases: a review. Gastroenterol Res Pract 2012; 2012:676585

11 Snyder M. The bacterial flora of meconium specimens collected from sixty-four infants within four hours after delivery. J Pediatr 1936;9(5):624-632

12 Jiménez E, Marín ML, Martín R, et al. Is meconium from healthy newborns actually sterile? Res Microbiol 2008;159(3):187-193

13 DiGiulio DB. Diversity of microbes in amniotic fluid. Semin Fetal Neonatal Med 2012;17(1):2-11

14 DiGiulio DB, Romero R, Amogan HP, et al. Microbial prevalence, diversity and abundance in amniotic fluid during preterm labor: a molecular and culture-based investigation. PLOS ONE 2008;3(8): e3056

15 Steel JH, Malatos S, Kennea N, et al. Bacteria and inflammatory cells in fetal membranes do not always cause preterm labor. Pediatr Res 2005;57(3):404-411

16 Jiménez E, Fernández L, Marín ML, et al. Isolation of commensal bacteria from umbilical cord blood of healthy neonates born by cesarean section. Curr Microbiol 2005;51(4):270-274

17 Satokari R, Grönroos T, Laitinen K, Salminen S, Isolauri E. Bifidobacterium and Lactobacillus DNA in the human placenta. Lett Appl Microbiol 2009;48(1):8-12

18 Pettker CM, Buhimschi IA, Magloire LK, Sfakianaki AK, Hamar BD, Buhimschi CS. Value of placental microbial evaluation in diagnosing intra-amniotic infection. Obstet Gynecol 2007;109(3): 739-749

19 Martin R, Langa S, Reviriego C, et al. The commensal microflora of human milk: New perspectives for food bacteriotherapy and probiotics. Trends Food Sci Technol 2004;14:121-127

20 Thum C, Cookson AL, Otter DE, et al. Can nutritional modulation of maternal intestinal microbiota influence the development of the infant gastrointestinal tract? J Nutr 2012;142(11):1921-1928

21 Bearfield C, Davenport ES, Sivapathasundaram V, Allaker RP. Possible association between amniotic fluid micro-organism infection and microflora in the mouth. BJOG 2002;109(5): 527-533

22 Wagner CL, Taylor SN, Johnson D. Host factors in amniotic fluid and breast milk that contribute to gut maturation. Clin Rev Allergy Immunol 2008;34(2):191-204

23 Blakey JL, Lubitz L, Barnes GL, Bishop RF, Campbell NT, Gillam GL. Development of gut colonisation in pre-term neonates. J Med Microbiol 1982;15(4):519-529

24 Magne F, Abély M, Boyer F, Morville P, Pochart P, Suau A. Low species diversity and high interindividual variability in faeces of preterm infants as revealed by sequences of $16 \mathrm{~S}$ rRNA genes and PCR-temporal temperature gradient gel electrophoresis profiles. FEMS Microbiol Ecol 2006;57(1):128-138

25 Sakata H, Yoshioka H, Fujita K. Development of the intestinal flora in very low birth weight infants compared to normal full-term newborns. Eur J Pediatr 1985;144(2):186-190

26 Gewolb IH, Schwalbe RS, Taciak VL, Harrison TS, Panigrahi P. Stool microflora in extremely low birthweight infants. Arch Dis Child Fetal Neonatal Ed 1999;80(3):F167-F173

27 Westerbeek EA, van den Berg A, Lafeber HN, Knol J, Fetter WP, van Elburg RM. The intestinal bacterial colonisation in preterm infants: a review of the literature. Clin Nutr 2006;25(3):361-368

28 Butel MJ, Suau A, Campeotto F, et al. Conditions of bifidobacterial colonization in preterm infants: a prospective analysis. J Pediatr Gastroenterol Nutr 2007;44(5):577-582

29 Jacquot A, Neveu D, Aujoulat F, et al. Dynamics and clinical evolution of bacterial gut microflora in extremely premature patients. J Pediatr 2011;158(3):390-396 
30 Scholtens PA, Oozeer R, Martin R, Amor KB, Knol J. The early settlers: intestinal microbiology in early life. Annu Rev Food Sci Technol 2012;3:425-447

31 Claud EC, Walker WA. Hypothesis: inappropriate colonization of the premature intestine can cause neonatal necrotizing enterocolitis. FASEB J 2001;15(8):1398-1403

32 Mai V, Young CM, Ukhanova M, et al. Fecal microbiota in premature infants prior to necrotizing enterocolitis. PLoS ONE 2011; 6(6):e20647

33 Dominguez-Bello MG, Costello EK, Contreras M, et al. Delivery mode shapes the acquisition and structure of the initial microbiota across multiple body habitats in newborns. Proc Natl Acad Sci U S A 2010;107(26):11971-11975

34 Biasucci G, Benenati B, Morelli L, Bessi E, Boehm G. Cesarean delivery may affect the early biodiversity of intestinal bacteria. J Nutr 2008;138(9):1796S-1800S

35 Penders J, Thijs C, Vink C, et al. Factors influencing the composition of the intestinal microbiota in early infancy. Pediatrics 2006; 118(2):511-521

36 Harmsen HJ, Wildeboer-Veloo AC, Raangs GC, et al. Analysis of intestinal flora development in breast-fed and formula-fed infants by using molecular identification and detection methods. J Pediatr Gastroenterol Nutr 2000;30(1):61-67

37 Yatsunenko T, Rey FE, Manary MJ, et al. Human gut microbiome viewed across age and geography. Nature 2012;486(7402): 222-227

38 Adlerberth I, Wold AE. Establishment of the gut microbiota in Western infants. Acta Paediatr 2009;98(2):229-238

39 Kunz C, Rudloff S, Baier W, Klein N, Strobel S. Oligosaccharides in human milk: structural, functional, and metabolic aspects. Annu Rev Nutr 2000;20:699-722

40 Martín-Sosa S, Martín MJ, García-Pardo LA, Hueso P. Sialyloligosaccharides in human and bovine milk and in infant formulas: variations with the progression of lactation. J Dairy Sci 2003; 86(1):52-59

41 Marcobal A, Barboza M, Froehlich JW, et al. Consumption of human milk oligosaccharides by gut-related microbes. J Agric Food Chem 2010;58(9):5334-5340

42 Marcobal A, Barboza M, Sonnenburg ED, et al. Bacteroides in the infant gut consume milk oligosaccharides via mucus-utilization pathways. Cell Host Microbe 2011;10(5):507-514

43 Fernández L, Langa S, Martín V, et al. The human milk microbiota: origin and potential roles in health and disease. Pharmacol Res 2013;69(1):1-10

44 Koenig JE, Spor A, Scalfone N, et al. Succession of microbial consortia in the developing infant gut microbiome. Proc Natl Acad Sci U S A 2011;108(Suppl 1):4578-4585

45 Fallani M, Amarri S, Uusijarvi A, et al; INFABIO team. Determinants of the human infant intestinal microbiota after the introduction of first complementary foods in infant samples from five European centres. Microbiology 2011;157(Pt 5):1385-1392

46 Roberfroid M, Gibson GR, Hoyles L, et al. Prebiotic effects: metabolic and health benefits. Br J Nutr 2010;104(Suppl 2): S1-S63

47 Haarman M, Knol J. Quantitative real-time PCR assays to identify and quantify fecal Bifidobacterium species in infants receiving a prebiotic infant formula. Appl Environ Microbiol 2005;71(5): 2318-2324

48 Veereman G. Pediatric applications of inulin and oligofructose. J Nutr 2007;137(11, Suppl):2585S-2589S

49 Salvini F, Riva E, Salvatici E, et al. A specific prebiotic mixture added to starting infant formula has long-lasting bifidogenic effects. J Nutr 2011;141(7):1335-1339

50 Shadid R, Haarman M, Knol J, et al. Effects of galactooligosaccharide and long-chain fructooligosaccharide supplementation during pregnancy on maternal and neonatal microbiota and immunity-a randomized, double-blind, placebo-controlled study. Am J Clin Nutr 2007;86(5):1426-1437
51 Food and Agriculture Organization/World Health Organization. Health and Nutritional Properties of Probiotics in Food Including Powder Milk with Live Lactic Acid Bacteria. 2001. Available at: http://www.who.int/foodsafety/publications/s_management/ probiotics/en/. Accessed on December 3, 2013

52 Grześkowiak L, Grönlund MM, Beckmann C, Salminen S, von Berg $\mathrm{A}$, Isolauri $\mathrm{E}$. The impact of perinatal probiotic intervention on gut microbiota: double-blind placebo-controlled trials in Finland and Germany. Anaerobe 2012;18(1):7-13

53 Tanaka S, Kobayashi T, Songjinda P, et al. Influence of antibiotic exposure in the early postnatal period on the development of intestinal microbiota. FEMS Immunol Med Microbiol 2009;56(1): 80-87

54 Fouhy F, Guinane CM, Hussey S, et al. High-throughput sequencing reveals the incomplete, short-term recovery of infant gut microbiota following parenteral antibiotic treatment with ampicillin and gentamicin. Antimicrob Agents Chemother 2012; 56(11):5811-5820

55 Van de Merwe JP, Stegeman JH, Hazenberg MP. The resident faecal flora is determined by genetic characteristics of the host. Implications for Crohn's disease? Antonie van Leeuwenhoek 1983; 49(2):119-124

56 Stewart JA, Chadwick VS, Murray A. Investigations into the influence of host genetics on the predominant eubacteria in the faecal microflora of children. J Med Microbiol 2005;54(Pt 12):1239-1242

57 Zoetendal EG, Akkermans ADL, Akkermans-van Vliet WM, de Visser JAGM, de Vos WM. The host genotype affects the bacterial community in the human gastrointestinal tract. Microb Ecol Health Dis 2001;13(3):129-134

58 Turnbaugh PJ, Hamady M, Yatsunenko T, et al. A core gut microbiome in obese and lean twins. Nature 2009;457(7228): 480-484

59 Benson AK, Kelly SA, Legge R, et al. Individuality in gut microbiota composition is a complex polygenic trait shaped by multiple environmental and host genetic factors. Proc Natl Acad Sci U S A 2010;107(44):18933-18938

60 McKnite AM, Perez-Munoz ME, Lu L, et al. Murine gut microbiota is defined by host genetics and modulates variation of metabolic traits. PLoS ONE 2012;7(6):e39191

61 Kaplan JL, Shi HN, Walker WA. The role of microbes in developmental immunologic programming. Pediatr Res 2011;69(6): 465-472

62 Vael C, Desager K. The importance of the development of the intestinal microbiota in infancy. Curr Opin Pediatr 2009;21(6): 794-800

63 Murgas Torrazza R, Neu J. The developing intestinal microbiome and its relationship to health and disease in the neonate. J Perinatol 2011;31(Suppl 1):S29-S34

64 Lai CK, Beasley R, Crane J, Foliaki S, Shah J, Weiland S; International Study of Asthma and Allergies in Childhood Phase Three Study Group. Global variation in the prevalence and severity of asthma symptoms: phase three of the International Study of Asthma and Allergies in Childhood (ISAAC). Thorax 2009;64(6): 476-483

65 Mannino DM, Homa DM, Pertowski CA, et al. Surveillance for asthma-United States, 1960-1995. MMWR CDC Surveill Summ 1998;47(1):1-27

66 Beasley R, Crane J, Lai CK, Pearce N. Prevalence and etiology of asthma. J Allergy Clin Immunol 2000;105(2, Pt 2):S466-S472

67 Asher MI, Keil U, Anderson HR, et al. International study of asthma and allergies in childhood (ISAAC): rationale and methods. Eur Respir J 1995;8(3):483-491

68 Strachan DP. Hay fever, hygiene, and household size. BMJ 1989; 299(6710):1259-1260

69 Björkstén B, Naaber P, Sepp E, Mikelsaar M. The intestinal microflora in allergic Estonian and Swedish 2-year-old children. Clin Exp Allergy 1999;29(3):342-346 
70 Fukuda S, Ishikawa H, Koga Y, et al. Allergic symptoms and microflora in schoolchildren. J Adolesc Health 2004;35(2): 156-158

71 Kalliomäki M, Kirjavainen P, Eerola E, Kero P, Salminen S, Isolauri E. Distinct patterns of neonatal gut microflora in infants in whom atopy was and was not developing. J Allergy Clin Immunol 2001; 107(1):129-134

72 Penders J, Thijs C, van den Brandt PA, et al. Gut microbiota composition and development of atopic manifestations in infancy: the KOALA Birth Cohort Study. Gut 2007;56(5):661-667

73 Rautava S, Kalliomäki M, Isolauri E. New therapeutic strategy for combating the increasing burden of allergic disease: Probiotics-A Nutrition, Allergy, Mucosal Immunology and Intestinal Microbiota (NAMI) Research Group report. J Allergy Clin Immunol 2005;116(1):31-37

74 Huffnagle GB. The microbiota and allergies/asthma. PLoS Pathog 2010;6(5):e1000549

75 Noverr MC, Huffnagle GB. The 'microflora hypothesis' of allergic diseases. Clin Exp Allergy 2005;35(12):1511-1520

76 Vael C, Vanheirstraeten L, Desager KN, Goossens H. Denaturing gradient gel electrophoresis of neonatal intestinal microbiota in relation to the development of asthma. BMC Microbiol 2011; $11: 68-2180$

77 Thavagnanam S, Fleming J, Bromley A, Shields MD, Cardwell CR. A meta-analysis of the association between Caesarean section and childhood asthma. Clin Exp Allergy 2008;38(4):629-633

78 Bager P, Melbye M, Rostgaard K, Benn CS, Westergaard T. Mode of delivery and risk of allergic rhinitis and asthma. J Allergy Clin Immunol 2003;111(1):51-56

79 van Nimwegen FA, Penders J, Stobberingh EE, et al. Mode and place of delivery, gastrointestinal microbiota, and their influence on asthma and atopy. J Allergy Clin Immunol 2011;128(5): 948-955, e1-e3

80 Mai XM, Kull I, Wickman M, Bergström A. Antibiotic use in early life and development of allergic diseases: respiratory infection as the explanation. Clin Exp Allergy 2010;40(8):1230-1237

81 Jedrychowski W, Perera F, Maugeri U, et al. Wheezing and asthma may be enhanced by broad spectrum antibiotics used in early childhood. Concept and results of a pharmacoepidemiology study. J Physiol Pharmacol 2011;62(2):189-195

82 Russell SL, Gold MJ, Hartmann M, et al. Early life antibiotic-driven changes in microbiota enhance susceptibility to allergic asthma. EMBO Rep 2012;13(5):440-447

83 Kull I, Melen E, Alm J, et al. Breast-feeding in relation to asthma, lung function, and sensitization in young schoolchildren.J Allergy Clin Immunol 2010;125(5):1013-1019

84 Kusunoki T, Morimoto T, Nishikomori R, et al. Breastfeeding and the prevalence of allergic diseases in schoolchildren: does reverse causation matter? Pediatr Allergy Immunol 2010;21(1, Pt 1): 60-66

85 Pohlabeln H, Mühlenbruch K, Jacobs S, Böhmann H. Frequency of allergic diseases in 2-year-old children in relationship to parental history of allergy and breastfeeding. J Investig Allergol Clin Immunol 2010;20(3):195-200

86 Wright AL, Holberg CJ, Taussig LM, Martinez F. Maternal asthma status alters relation of infant feeding to asthma in childhood. Adv Exp Med Biol 2000;478:131-137

87 Grönlund MM, Gueimonde M, Laitinen K, et al. Maternal breast-milk and intestinal bifidobacteria guide the compositional development of the Bifidobacterium microbiota in infants at risk of allergic disease. Clin Exp Allergy 2007;37(12): 1764-1772

88 Asher MI, Montefort S, Björkstén B, et al; ISAAC Phase Three Study Group. Worldwide time trends in the prevalence of symptoms of asthma, allergic rhinoconjunctivitis, and eczema in childhood: ISAAC Phases One and Three repeat multicountry cross-sectional surveys. Lancet 2006;368(9537):733-743
89 Shaw TE, Currie GP, Koudelka CW, Simpson EL. Eczema prevalence in the united states: Data from the 2003 national survey of children's health. J Invest Dermatol 2011;131(1):67-73

90 Gore C, Munro K, Lay C, et al. Bifidobacterium pseudocatenulatum is associated with atopic eczema: a nested case-control study investigating the fecal microbiota of infants. J Allergy Clin Immunol 2008;121(1):135-140

91 Wang M, Karlsson C, Olsson C, et al. Reduced diversity in the early fecal microbiota of infants with atopic eczema. J Allergy Clin Immunol 2008;121(1):129-134

92 Abrahamsson TR, Jakobsson HE, Andersson AF, Björkstén B, Engstrand L, Jenmalm MC. Low diversity of the gut microbiota in infants with atopic eczema. J Allergy Clin Immunol 2012; 129(2):434-440, e1-e2

93 Ismail IH, Oppedisano F, Joseph SJ, et al. Reduced gut microbial diversity in early life is associated with later development of eczema but not atopy in high-risk infants. Pediatr Allergy Immunol 2012;23(7):674-681

94 Foliaki S, Pearce N, Björkstén B, Mallol J, Montefort S, von Mutius E; International Study of Asthma and Allergies in Childhood Phase III Study Group. Antibiotic use in infancy and symptoms of asthma, rhinoconjunctivitis, and eczema in children 6 and 7 years old: International Study of Asthma and Allergies in Childhood Phase III. J Allergy Clin Immunol 2009;124(5): 982-989

95 Greer FR, Sicherer SH, Burks AW; American Academy of Pediatrics Committee on Nutrition; American Academy of Pediatrics Section on Allergy and Immunology. Effects of early nutritional interventions on the development of atopic disease in infants and children: the role of maternal dietary restriction, breastfeeding, timing of introduction of complementary foods, and hydrolyzed formulas. Pediatrics 2008;121(1):183-191

96 Ip S, Chung M, Raman G, et al. Breastfeeding and maternal and infant health outcomes in developed countries. Evid Rep Technol Assess (Full Rep) 2007;(153):1-186

97 Flohr C, Nagel G, Weinmayr G, Kleiner A, Strachan DP, Williams HC; ISAAC Phase Two Study Group. Lack of evidence for a protective effect of prolonged breastfeeding on childhood eczema: lessons from the International Study of Asthma and Allergies in Childhood (ISAAC) Phase Two. Br J Dermatol 2011;165(6): 1280-1289

98 Giwercman C, Halkjaer LB, Jensen SM, Bønnelykke K, Lauritzen L, Bisgaard $\mathrm{H}$. Increased risk of eczema but reduced risk of early wheezy disorder from exclusive breast-feeding in high-risk infants. J Allergy Clin Immunol 2010;125(4):866-871

99 Gigante G, Tortora A, Ianiro G, et al. Role of gut microbiota in food tolerance and allergies. Dig Dis 2011;29(6):540-549

100 Thompson-Chagoyan OC, Vieites JM, Maldonado J, Edwards C, Gil A. Changes in faecal microbiota of infants with cow's milk protein allergy-a Spanish prospective case-control 6-month follow-up study. Pediatr Allergy Immunol 2010;21(2, Pt 2):e394-e400

101 Thompson-Chagoyan OC, Fallani M, Maldonado J, et al. Faecal microbiota and short-chain fatty acid levels in faeces from infants with cow's milk protein allergy. Int Arch Allergy Immunol 2011; 156(3):325-332

102 Rodriguez B, Prioult G, Bibiloni R, et al. Germ-free status and altered caecal subdominant microbiota are associated with a high susceptibility to cow's milk allergy in mice. FEMS Microbiol Ecol 2011;76(1):133-144

103 Rodriguez B, Prioult G, Hacini-Rachinel F, et al. Infant gut microbiota is protective against cow's milk allergy in mice despite immature ileal T-cell response. FEMS Microbiol Ecol 2012;79(1): 192-202

104 Keski-Nisula L, Karvonen A, Pfefferle PI, Renz H, Büchele G, Pekkanen J. Birth-related factors and doctor-diagnosed wheezing and allergic sensitization in early childhood. Allergy 2010;65(9): 1116-1125 
105 Koplin JJ, Martin PE, Tang MLK, et al. Do factors known to alter infant microbial exposures alter the risk of food allergy and eczema in a population-based infant study? J Allergy Clin Immunol 2012;129(2, Suppl):ABC231

106 Eggesbø M, Botten G, Stigum H, Nafstad P, Magnus P. Is delivery by cesarean section a risk factor for food allergy? J Allergy Clin Immunol 2003;112(2):420-426

107 Eggesbø M, Botten G, Stigum H, Samuelsen SO, Brunekreef B, Magnus P. Cesarean delivery and cow milk allergy/intolerance. Allergy 2005;60(9):1172-1173

108 Carlisle EM, Morowitz MJ. The intestinal microbiome and necrotizing enterocolitis. Curr Opin Pediatr 2013;25(3):382-387

109 Grishin A, Papillon S, Bell B, Wang J, Ford HR. The role of the intestinal microbiota in the pathogenesis of necrotizing enterocolitis. Semin Pediatr Surg 2013;22(2):69-75

110 Mshvildadze M, Neu J, Shuster J, Theriaque D, Li N, Mai V. Intestinal microbial ecology in premature infants assessed with non-culture-based techniques. J Pediatr 2010;156(1): $20-25$

111 Normann E, Fahlén A, Engstrand L, Lilja HE. Intestinal microbial profiles in extremely preterm infants with and without necrotizing enterocolitis. Acta Paediatr 2013;102(2):129-136

112 Stewart CJ, Marrs EC, Magorrian S, et al. The preterm gut microbiota: changes associated with necrotizing enterocolitis and infection. Acta Paediatr 2012;101(11):1121-1127

113 Comito D, Romano C. Dysbiosis in the pathogenesis of pediatric inflammatory bowel diseases. Int J Inflamm 2012;2012:687143

114 Cucchiara S, Iebba V, Conte MP, Schippa S. The microbiota in inflammatory bowel disease in different age groups. Dig Dis 2009;27(3):252-258

115 Aomatsu T, Imaeda $\mathrm{H}$, Fujimoto $\mathrm{T}$, et al. Terminal restriction fragment length polymorphism analysis of the gut microbiota profiles of pediatric patients with inflammatory bowel disease. Digestion 2012;86(2):129-135

116 Schwiertz A, Jacobi M, Frick JS, Richter M, Rusch K, Köhler H. Microbiota in pediatric inflammatory bowel disease. J Pediatr 2010;157(2):240-244, e1

117 Michail S, Durbin M, Turner D, et al. Alterations in the gut microbiome of children with severe ulcerative colitis. Inflamm Bowel Dis 2012;18(10):1799-1808

118 Conte MP, Schippa S, Zamboni I, et al. Gut-associated bacterial microbiota in paediatric patients with inflammatory bowel disease. Gut 2006;55(12):1760-1767

119 Negroni A, Costanzo M, Vitali R, et al. Characterization of adherent-invasive Escherichia coli isolated from pediatric patients with inflammatory bowel disease. Inflamm Bowel Dis 2012;18(5): 913-924

120 Bager P, Simonsen J, Nielsen NM, Frisch M. Cesarean section and offspring's risk of inflammatory bowel disease: a national cohort study. Inflamm Bowel Dis 2012;18(5):857-862

121 Decker E, Engelmann G, Findeisen A, et al. Cesarean delivery is associated with celiac disease but not inflammatory bowel disease in children. Pediatrics 2010;125(6):e1433-e1440

122 Klement E, Cohen RV, Boxman J, Joseph A, Reif S. Breastfeeding and risk of inflammatory bowel disease: a systematic review with meta-analysis. Am J Clin Nutr 2004;80(5):1342-1352

123 Barclay AR, Russell RK, Wilson ML, Gilmour WH, Satsangi J, Wilson DC. Systematic review: the role of breastfeeding in the development of pediatric inflammatory bowel disease. J Pediatr 2009;155(3):421-426

124 Kronman MP, Zaoutis TE, Haynes K, Feng R, Coffin SE. Antibiotic exposure and IBD development among children: a populationbased cohort study. Pediatrics 2012;130(4):e794-e803

125 Virta L, Auvinen A, Helenius H, Huovinen P, Kolho KL. Association of repeated exposure to antibiotics with the development of pediatric Crohn's disease-a nationwide, register-based Finnish case-control study. Am J Epidemiol 2012;175(8): 775-784
126 Shaw SY, Blanchard JF, Bernstein CN. Association between the use of antibiotics in the first year of life and pediatric inflammatory bowel disease. Am J Gastroenterol 2010;105(12):2687-2692

127 Hviid A, Svanström H, Frisch M. Antibiotic use and inflammatory bowel diseases in childhood. Gut 2011;60(1):49-54

128 Aujnarain A, Mack DR, Benchimol EI. The role of the environment in the development of pediatric inflammatory bowel disease. Curr Gastroenterol Rep 2013;15(6):326-013

129 Longstreth GF, Thompson WG, Chey WD, Houghton LA, Mearin F, Spiller RC. Functional bowel disorders. Gastroenterology 2006; 130(5):1480-1491

130 Saulnier DM, Riehle K, Mistretta TA, et al. Gastrointestinal microbiome signatures of pediatric patients with irritable bowel syndrome. Gastroenterology 2011;141(5):1782-1791

131 Rigsbee L, Agans R, Shankar V, et al. Quantitative profiling of gut microbiota of children with diarrhea-predominant irritable bowel syndrome. Am J Gastroenterol 2012;107(11):1740-1751

132 Maxwell PR, Rink E, Kumar D, Mendall MA. Antibiotics increase functional abdominal symptoms. Am J Gastroenterol 2002;97(1): 104-108

133 Ismail IH, Licciardi PV, Tang ML. Probiotic effects in allergic disease. J Paediatr Child Health 2013;49(9):709-715

134 Fiocchi A, Burks W, Bahna SL, et al; WAO Special Committee on Food Allergy and Nutrition. Clinical use of probiotics in pediatric allergy (CUPPA): A world allergy organization position paper. World Allergy Organ J 2012;5(11):148-167

135 Soh SE, Aw M, Gerez I, et al. Probiotic supplementation in the first 6 months of life in at risk Asian infants-effects on eczema and atopic sensitization at the age of 1 year. Clin Exp Allergy 2009; 39(4):571-578

136 Taylor AL, Dunstan JA, Prescott SL. Probiotic supplementation for the first 6 months of life fails to reduce the risk of atopic dermatitis and increases the risk of allergen sensitization in high-risk children: a randomized controlled trial. J Allergy Clin Immunol 2007;119(1):184-191

137 Boyle RJ, Ismail IH, Kivivuori S, et al. Lactobacillus GG treatment during pregnancy for the prevention of eczema: a randomized controlled trial. Allergy 2011;66(4):509-516

138 West CE, Hammarström ML, Hernell O. Probiotics during weaning reduce the incidence of eczema. Pediatr Allergy Immunol 2009; 20(5):430-437

139 Weston S, Halbert A, Richmond P, Prescott SL. Effects of probiotics on atopic dermatitis: a randomised controlled trial. Arch Dis Child 2005;90(9):892-897

140 Woo SI, Kim JY, Lee YJ, Kim NS, Hahn YS. Effect of Lactobacillus sakei supplementation in children with atopic eczema-dermatitis syndrome. Ann Allergy Asthma Immunol 2010;104(4):343-348

141 Fölster-Holst R, Müller F, Schnopp N, et al. Prospective, randomized controlled trial on Lactobacillus rhamnosus in infants with moderate to severe atopic dermatitis. Br J Dermatol 2006;155(6): 1256-1261

142 Osborn DA, Sinn JK. Prebiotics in infants for prevention of allergy. Cochrane Database Syst Rev 2013;3:CD006474

143 Gupta P, Andrew H, Kirschner BS, Guandalini S. Is lactobacillus GG helpful in children with Crohn's disease? Results of a preliminary, open-label study. J Pediatr Gastroenterol Nutr 2000;31(4):453-457

144 Bousvaros A, Guandalini S, Baldassano RN, et al. A randomized, double-blind trial of Lactobacillus GG versus placebo in addition to standard maintenance therapy for children with Crohn's disease. Inflamm Bowel Dis 2005;11(9):833-839

145 Prantera C, Scribano ML, Falasco G, Andreoli A, Luzi C. Ineffectiveness of probiotics in preventing recurrence after curative resection for Crohn's disease: a randomised controlled trial with Lactobacillus GG. Gut 2002;51(3):405-409

146 Rahimi R, Nikfar S, Rahimi F, et al. A meta-analysis on the efficacy of probiotics for maintenance of remission and prevention of clinical and endoscopic relapse in Crohn's disease. Dig Dis Sci 2008;53(9):2524-2531 
147 Miele E, Pascarella F, Giannetti E, Quaglietta L, Baldassano RN, Staiano A. Effect of a probiotic preparation (VSL\#3) on induction and maintenance of remission in children with ulcerative colitis. Am J Gastroenterol 2009;104(2):437-443

148 Huynh HQ deBruyn J, Guan L, et al. Probiotic preparation VSL\#3 induces remission in children with mild to moderate acute ulcerative colitis: a pilot study. Inflamm Bowel Dis 2009;15(5):760-768

149 Tursi A, Brandimarte G, Giorgetti GM, Forti G, Modeo ME, Gigliobianco A. Low-dose balsalazide plus a high-potency probiotic preparation is more effective than balsalazide alone or mesalazine in the treatment of acute mild-to-moderate ulcerative colitis. Med Sci Monit 2004;10(11):PI126-PI131

150 Bibiloni R, Fedorak RN, Tannock GW, et al. VSL\#3 probioticmixture induces remission in patients with active ulcerative colitis. Am J Gastroenterol 2005;100(7):1539-1546

151 Oliva S, Di Nardo G, Ferrari F, et al. Randomised clinical trial: the effectiveness of Lactobacillus reuteri ATCC 55730 rectal enema in children with active distal ulcerative colitis. Aliment Pharmacol Ther 2012;35(3):327-334

152 Floch MH, Walker WA, Madsen K, et al. Recommendations for probiotic use-2011 update. J Clin Gastroenterol 2011;45(Suppl): S168-S171

153 Guandalini S. Update on the role of probiotics in the therapy of pediatric inflammatory bowel disease. Expert Rev Clin Immunol 2010;6(1):47-54

154 Welters CF, Heineman E, Thunnissen FB, van den Bogaard AE, Soeters PB, Baeten CG. Effect of dietary inulin supplementation on inflammation of pouch mucosa in patients with an ileal pouchanal anastomosis. Dis Colon Rectum 2002;45(5):621-627

155 Mitsuyama K, Saiki T, Kanauchi O, et al. Treatment of ulcerative colitis with germinated barley foodstuff feeding: a pilot study. Aliment Pharmacol Ther 1998;12(12):1225-1230

156 Lindsay JO, Whelan K, Stagg AJ, et al. Clinical, microbiological, and immunological effects of fructo-oligosaccharide in patients with Crohn's disease. Gut 2006;55(3):348-355

157 Moayyedi P, Ford AC, Talley NJ, et al. The efficacy of probiotics in the treatment of irritable bowel syndrome: a systematic review. Gut 2010;59(3):325-332

158 Whelan K. Probiotics and prebiotics in the management of irritable bowel syndrome: a review of recent clinical trials and systematic reviews. Curr Opin Clin Nutr Metab Care 2011;14(6): $581-587$
159 Huertas-Ceballos AA, Logan S, Bennett C, Macarthur C. Dietary interventions for recurrent abdominal pain (RAP) and irritable bowel syndrome (IBS) in childhood. Cochrane Database Syst Rev 2009;(1):CD003019

160 Francavilla R, Miniello V, Magistà AM, et al. A randomized controlled trial of Lactobacillus GG in children with functional abdominal pain. Pediatrics 2010;126(6):e1445-e1452

161 Guandalini S, Magazzù G, Chiaro A, et al. VSL\#3 improves symptoms in children with irritable bowel syndrome: a multicenter, randomized, placebo-controlled, double-blind, crossover study. J Pediatr Gastroenterol Nutr 2010;51(1):24-30

162 Staudacher HM, Whelan K, Irving PM, Lomer MC. Comparison of symptom response following advice for a diet low in fermentable carbohydrates (FODMAPs) versus standard dietary advice in patients with irritable bowel syndrome. J Hum Nutr Diet 2011; 24(5):487-495

163 Alfaleh K, Anabrees J, Bassler D, Al-Kharfi T. Probiotics for prevention of necrotizing enterocolitis in preterm infants. Cochrane Database Syst Rev 2011;(3):CD005496

164 Downard CD, Renaud E, St Peter SD, et al; 2012 American Pediatric Surgical Association Outcomes Clinical Trials Committee. Treatment of necrotizing enterocolitis: An American pediatric surgical association outcomes and clinical trials committee systematic review. J Pediatr Surg 2012;47(11):2111-2122

165 Fallon EM, Nehra D, Potemkin AK, et al; American Society for Parenteral and Enteral Nutrition (A.S.P.E.N.) Board of Directors. A. S.P.E.N. clinical guidelines: nutrition support of neonatal patients at risk for necrotizing enterocolitis. JPEN J Parenter Enteral Nutr 2012;36(5):506-523

166 Lee JH. An update on necrotizing enterocolitis: pathogenesis and preventive strategies. Korean J Pediatr 2011;54(9):368-372

167 Vandenplas Y, De Greef E, Devreker T, Veereman-Wauters G, Hauser B. Probiotics and prebiotics in infants and children. Curr Infect Dis Rep 2013;15(3):251-262

168 Chapkin RS, Zhao C, Ivanov I, et al. Noninvasive stool-based detection of infant gastrointestinal development using gene expression profiles from exfoliated epithelial cells. Am J Physiol Gastrointest Liver Physiol 2010;298(5):G582-G589

169 Schwartz S, Friedberg I, Ivanov IV, et al. A metagenomic study of diet-dependent interaction between gut microbiota and host in infants reveals differences in immune response. Genome Biol 2012;13(4):r32-r2012 